\title{
Regulator of Telomere Elongation Helicase 1
}

National Cancer Institute

\section{Source}

National Cancer Institute. Regulator of Telomere Elongation Helicase 1. NCI Thesaurus.

Code C134634.

Regulator of telomere elong ation helicase 1 (1219 aa, 134 kDa) is encoded by the

human RTEL1 gene. This protein plays a role in the maintenance of chromosomes and telomeres. 